\title{
Potencialidades do PPP no Software Bernese com Compatibilizações de Sistemas Geodésicos de Referência e de Tempo
}

\author{
Potentialities of PPP in the BERNESE GNSS Software with \\ Compatibilization of Geodetic Reference System and Time
}

\author{
Franciele Lúcia Silva Braga ${ }^{1}$ \\ William Rodrigo Dal Poz ${ }^{2}$
}

Recebido em março de 2019.

Aprovado em julho de 2019.

\begin{abstract}
RESUMO
O Software Bernese GNSS (BSW) é um conjunto de pacotes de processamento de observáveis GNSS (Global Navigation Satellite System) de alto desempenho, que proporciona estimativas com alta acurácia, e flexibilidade em suas aplicações. Uma destas funcionalidades é a automatização de scripts que realizam o Posicionamento por Ponto Preciso (PPP). O objetivo deste trabalho é analisar as potencialidades do PPP no BSW. Para alcançar esse propósito foram estimadas as coordenadas de 90 estações da RBMC (Rede Brasileira de Monitoramento Contínuo dos Sistemas GNSS) no BSW e no serviço IBGE-PPP online, referenciadas a atual realização do International GNSS Service, o IGS14, na época dos dados. As coordenadas estimadas foram comparadas com as coordenadas de referência das estações (SIRGAS2000, época 2000,40), de três formas distintas: 1. Referenciais e épocas incompatíveis; 2. Compatibilização apenas dos referenciais; e 3. Referenciais e épocas compatíveis. As acurácias das coordenadas reduziram no processo de compatibilização de referenciais. Como esperado, o fator predominante na alteração das coordenadas planimétricas se refere à sua evolução temporal. Ademais, as acurácias planimétricas e altimétricas apresentaram estatísticas descritivas similares ao nível do milímetro, evidenciando a potencialidade do BSW no PPP.
\end{abstract}

PALAVRAS-CHAVE: PPP. Bernese. IBGE-PPP. IGS14. SIRGAS2000. GNSS. Transformação de referenciais. acurácia.

\begin{abstract}
Bernese GNSS Software (BSW) is a set of post-processing GNSS (Global Navigation Satellite System) packages providing high-performance processing, that provides estimates with high accuracy and flexibility in
\end{abstract}

\footnotetext{
1Universidade Federal de Viçosa - UFV. Programa de Pós-graduação em Eng. Civil, Área de concentração em Informações Espaciais, Brasil. E-mail: franciele.braga@ufv.br

${ }^{2}$ Universidade Federal de Viçosa -UFV. Programa de Pós-graduação em Eng. Civil, Área de concentração em Informações Espaciais, Brasil. E-mail: william.dalpoz@ufv.br
} 
their applications. One of these features is the automation of scripts that perform Precise Point Positioning (PPP). The purpose of this paper is to analyze the potential of PPP in BSW. To achieve this goal, the coordinates of 90 stations from RBMC (Brazilian Network for Continuous Monitoring of GNSS Systems) were estimated in BSW and in the online IBGE-PPP service, in the current realization of the International GNSS Service, the IGS14, epoch of data. Then, they were compared with the reference coordinates of the stations (SIRGAS2000, epoch 2000.40), in three different ways: 1. Incompatible referential and epochs; 2. Referentials only compatibilization; and 3. Compatible referentials and epochs. The coordinate accuracy was reduced the process of compatibility of referentials. As expected, the predominant factor in the change in planimetric coordinates refers to their temporal evolution. In addition, the planimetric and altimetric accuracy presented descriptive statistics similar to the millimeter level, evidencing the potentiality of BSW in the PPP.

KEYWORDS: PPP. Bernese. IBGE-PPP. IGS14. SIRGAS2000. GNSS. Transformation of referentials. accuracy.

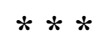

\section{Introdução}

O Software Bernese GNSS (BSW) é um pacote de softwares científicos, concebido e desenvolvido pelo Instituto Astronômico da Universidade de Berna, Suíça. Este software é amplamente empregado para estimativas de redes geodésicas de alta acurácia (DACH et al., 2015).

Uma das diversas aplicações de alto desempenho relacionadas ao pósprocessamento de observáveis GPS (Global Positioning System)/GLONASS (Global'naya Navigatsionnay Sputnikovaya Sistema) executadas no BSW é o Posicionamento por Ponto Preciso (PPP).

O PPP é um método de posicionamento GNSS em que é utilizado apenas um receptor. O processamento dos dados pode ser no modo pósprocessado e também em tempo real. A precisão do método pode ser ainda melhor com a utilização de receptores de dupla frequência, que corrige os efeitos de primeira ordem provindos da ionosfera, através da combinação linear das frequências L1 e L2, denominada livre dos efeitos da Ionosfera. Além disso, são utilizadas efemérides precisas e correções dos relógios dos satélites, as quais estão vinculadas a determinada época de referência (época 
de rastreio) e normalmente à rede materializada do International GNSS Service (IGS), atualmente denominada IGS14 (IGS, 2017; BRAGA e DAL POZ, 2017; CARVALHO e DAL POZ, 2014). Contudo, a maioria das fontes de erros envolvidas no GNSS precisa ser modelada, incluindo os efeitos geodinâmicos, ao contrário do que ocorre com o método de posicionamento relativo (MONICO, 2008).

A solução PPP no BSW consiste em várias etapas, incluindo a importação de dados, preparação de órbita, sincronização do relógio do receptor, deteç̧ão de perdas de ciclo e estimação de parâmetros, sendo eles: parâmetros de troposfera (ZWD - Zenith Wet Delay), coordenadas cartesianas da estação e correções do relógio do receptor (DACH et al., 2015).

Em relação à modelagem da ionosfera, o BSW v.5.2 apresentou uma melhoria em relação à versão anterior, com a possibilidade de análise e correção dos efeitos de segunda e terceira ordens da ionosfera, também conhecidos como efeitos de ordem superior (HOI). Muitas vezes os efeitos HOI são relevantes, com uso da combinação livre dos efeitos da ionosfera (L3) (DACH et al., 2015).

Soycan (2012) avaliou a qualidade do PPP GPS (Global Positioning System) no BSW v.5.0., para diferentes estações do IGS, e períodos do ano de 2007. Os RMSs (Root Mean Square) encontrados para o processamento de observáveis GPS, no intervalo de 24 horas, foram de 0,0031, 0,0058 e 0,0088 metros para os componentes norte, leste e up, respectivamente. Já Zhou, Kuang e Cai (2018) analisaram o efeito de ordem superior da ionosfera no PPP na China, usando o BSW. Os resultados desse estudo indicaram que os erros no posicionamento aumentam à medida que a latitude da estação diminui ou a atividade ionosférica aumenta.

Em vista disso, o objetivo desse trabalho é avaliar as potencialidades do PPP no BSW, em território brasileiro, considerando os procedimentos de compatibilizações de época e referencial. Para tal fim, foram comparados os resultados obtidos com técnica PPP em 90 estações da RBMC no BSW e no 
serviço IBGE-PPP online, em relação às coordenadas oficiais dessas estações, em oito dias para o ano de 2017.

No Brasil o sistema de referência oficial é o SIRGAS (Sistema de Referência Geocêntrico para as Américas), a datar do dia 25 de fevereiro de 2005, por meio da resolução 01/2005 da presidência do IBGE. Esse sistema tem sua realização no ano 2000 e época de referência 2000,40. Desta forma, as coordenadas de referências das estações GNSS pertencentes à RBMC, se encontram nesse referencial e época.

Já as coordenadas dos satélites obtidas por meio da utilização das efemérides precisas do IGS encontram-se referidas ao IGS14 (ITRF2014) desde do dia 29 de janeiro de 2017 (semana GPS 1934) (IGS, 2017). Em outras palavras, desde o dia 29/01/2017, todo os serviços de Posicionamento Por Ponto Preciso, incluindo o IBGE PPP online, passaram a fornecer as coordenadas estimadas referenciadas ao IGS14. Desse modo, as coordenadas estimadas das estações da RBMC estão associadas ao IGS14, e à época de rastreio das observações. Salienta-se que o IBGE-PPP também disponibiliza as coordenadas estimadas no referencial SIRGAS2000, na época do levantamento e na época 2000,40.

Nesse intuito, para alcançar o propósito deste estudo, as coordenadas estimadas e as de referência destas estações serão analisadas na mesma época de referência, com o objetivo de reduzir o efeito do movimento da placa tectônica, além da compatibilização do sistema de referência, de modo que as comparações possam ser efetuadas.

\section{Materiais e Métodos}

\subsection{Materiais utilizados}

No desenvolvimento deste trabalho foram utilizadas as coordenadas de referência de 90 estações (Figura 1) pertencentes à RBMC, disponibilizadas 
pelo IBGE em seus respectivos descritivos. As observáveis GNSS (arquivos RINEX), destas 90 estações, foram usadas com o intervalo de rastreio de 24 horas, para o dia 1 de março de 2017. Com esses arquivos foram realizados os pós processamentos no BSW v.5.2 e no IBGE-PPP. Além dos arquivos RINEX de observação das estações e órbitas precisas dos satélites fornecidas pelo CODE (Center for Orbit Determination in Europe) e NRCan (Natural Resources of Canada), também foram empregados os arquivos de DCBs (Differential Code Biases), os parâmetros do modelo de cargas oceânicas, e os arquivos de cargas atmosféricas. Além do mais, foram utilizados:

a) O software Matlab, versão R2012b, para a implementação da rotina de transformação de referenciais, atualização de coordenadas, e mudanças de referencial de velocidades, além dos cálculos das discrepâncias e acurácias planimétricas e altimétricas. Destaca-se que o Departamento de Engenharia Civil (DEC), da Universidade Federal de Viçosa (UFV), tem a licença do Matlab;

b) O software o ArcGIS 10.2, na espacialização das estações GNSS da RBMC empregues neste estudo (Figura 1);

c) Os parâmetros de transformação disponibilizados pelo IGN (Institut National de L'Information Géographique et Forestière). Estes foram usados no processo de transformação de referencial e atualização de coordenadas entre o IGS14, época de coleta dos dados, e o SIRGAS2000, época 2000,40 (IGN, 2017). Neste caso, considera-se a compatibilidade entre o IGS14 e o ITRF2014 (REBISCHUNG, 2016) e entre o SIRGAS2000 e o ITRF2000 (WESTON e SOLER, 2012);

d) Mapas ionosféricos globais do CODE, necessários na correção dos efeitos HOI no BSW; e

e) Os coeficientes da função de mapeamento VMF1 (Vienna Mapping Function 1). Esses parâmetros são fornecidos em um grid global $\left(2,0^{\circ}\right.$ de latitude $\times 2,5^{\circ}$ longitude) a cada seis horas, que é a resolução temporal usual de dados do ECMWF (European Centre for MediumRange Weather Forecasts) (VMF1, 2017). 
Figura 1- Espacialização das estações da RBMC utilizadas neste trabalho

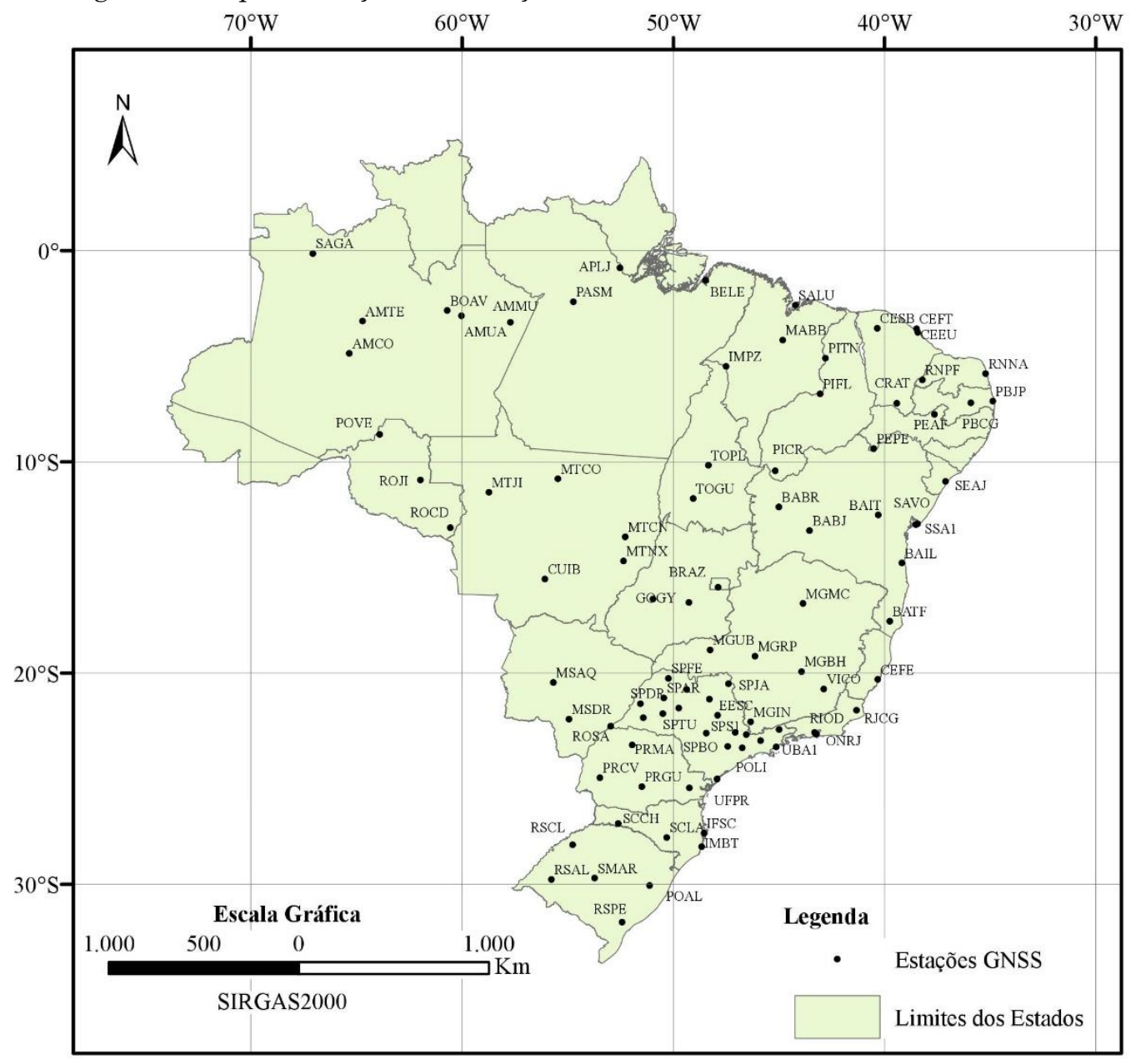

Fonte: Elaborada pelos autores.

\subsection{Metodologia}

A Quadro 1 apresenta um resumo de alguns parâmetros e as estratégias de processamentos executada no BSW e IBGE-PPP.

No serviço IBGE-PPP apenas foi inserido o arquivo de observação. Nesse aplicativo, o usuário apenas escolhe se o posicionamento é estático ou cinemático. Portanto, os demais parâmetros de processamento são padronizados, tais como, a máscara de elevação, função de mapeamento, combinação linear livre dos efeitos da ionosfera (L3) para receptores de dupla frequência, produtos orbitais, modelagem da troposfera, carga oceânica e marés terrestres. Além disso, os resultados possuem o mesmo intervalo de 
observação do arquivo de entrada. No BSW, por ser um software que aplica modelagem científica, a maioria desses parâmetros podem ser alterados, além de possuir ferramentas eficazes para automatização do processamento. Desta forma, apesar de não ser um programa livre, o mesmo oferece a vantagem de alteração nas estratégias de processamento.

Quadro 1 - Estratégia de processamento no BSW v.5.2 e IBGE-PPP

\begin{tabular}{|c|c|c|}
\hline Parâmetro & BSW & IBGE-PPP \\
\hline Intervalo das observações & 30 segundos & 30 segundos \\
\hline Produtos orbitais & $\begin{array}{c}\text { CODE finais / precisos } \\
\text { (GPS/GLONASS) }\end{array}$ & $\begin{array}{c}\text { NRCan finais / precisos } \\
\text { (GPS/GLONASS) }\end{array}$ \\
\hline Modelo de cargas oceânicas & FES2004 & FES2004 \\
\hline Modelo de carga atmosférica & Ray e Ponte ( 2003) & - \\
\hline Maré Terrestre & IERS Conventions, 2010 & IERS Conventions, 2010 \\
\hline $\begin{array}{c}\text { Parâmetros absolutos de } \\
\text { calibração e offset do centro } \\
\text { de fase das antenas dos } \\
\text { satélites e receptores }\end{array}$ & PCV.I14 (ANTEX format) & PCV.I14 (ANTEX format) \\
\hline Máscara de elevação & $10^{\circ}$ & $10^{\circ}$ \\
\hline Realização do referencial & IGS14 & IGS14 e SIRGAS2000 \\
\hline Sistemas GNSS & GPS e GLONASS & GPS e GLONASS \\
\hline Ionosfera & L3 e HOI & L3 \\
\hline $\begin{array}{c}\text { Modelo a priori do atraso } \\
\text { troposférico }\end{array}$ & VMF1/ECMWF* & $\begin{array}{c}\text { Modelo Davis/GPT2 (Global } \\
\text { Pressure and Temperature 2) }\end{array}$ \\
\hline Função de Mapeamento & VMF & GMF \\
\hline $\begin{array}{c}\text { Componente úmida do } \\
\text { atraso troposférico }\end{array}$ & Estimada & Estimada \\
\hline Gradientes horizontais & Estimado & Estimado \\
\hline $\begin{array}{c}\text { Modelo de Gradiente } \\
\text { CHENHER (Chen e Herring, }\end{array}$ & 1997) \\
\hline
\end{tabular}

Fonte: Elaborado pelos autores.

As coordenadas estimadas no BSW e no IBGE-PPP foram estimadas no referencial IGS14 (ITRF2014), na época de coleta dos dados, ou seja, na época 2017,16 (01/03/2017 - dia do ano 60). Desse modo, essas coordenadas estimadas foram comparadas com as coordenadas de referência das estações da RBMC, de acordo com três formas distintas:

a) Primeira forma: realizou-se o cálculo das acurácias das coordenadas obtidas no pós-processamento PPP (IGS14, época de coleta dos dados), 
em relação às coordenadas oficiais das estações, sendo estas referenciadas ao SIRGAS2000, época 2000,40;

b) Segunda forma: as coordenadas oficiais referenciadas ao SIRGAS2000, na época 2000,40, foram comparadas com as coordenadas estimadas, porém, estas foram transformadas para o ITRF2000, época de coleta dos dados, e;

c) Terceira forma: as coordenadas oficiais (SIRGAS2000, época 2000,40) foram comparadas com as coordenadas estimadas, porém, estas foram transformadas e atualizadas para o ITRF2000, época de referência $(2000,40)$.

Considerando a primeira forma, as acurácias entre as coordenadas estimadas (IGS14, época 2017,16) e as de referências (SIRGAS2000, época 2000,40), estarão relacionadas, tanto em relação aos referenciais distintos, quanto as épocas distintas, fazendo com que as coordenadas que foram estimadas em uma determinada época se alterem com o tempo (CARVALHO e DAL POZ, 2014; ALMEIDA, OLIVEIRA, e DAL POZ, 2016).

Na segunda forma, foi realizada a compatibilização de referencial entre as coordenadas estimadas e as de referência. Este procedimento possibilita que seja analisado o deslocamento das estações no intervalo de tempo entre a época de determinação das coordenadas de referência e a época de interesse, em consequência ao movimento da placa tectônica (CARVALHO e DAL POZ, 2014; ALMEIDA, OLIVEIRA, e DAL POZ, 2016).

$\mathrm{Na}$ terceira forma, foi realizada a compatibilização de referencial entre as coordenadas estimadas (IGS14 para SIRGAS2000) em conjunto com a compatibilização de épocas (época 2017,16 para 2000,40).

As etapas do processo de transformação de referencial e atualização de coordenadas, empregadas neste trabalho, consistem em: primeiramente são atualizados os parâmetros de transformação para a época de interesse; em seguida realiza-se a transformação de coordenadas; e por fim, as coordenadas são atualizadas, sendo que para tal, deve-se ter conhecimento da velocidade 
da estação. Uma descrição resumida dos principais passos é apresentada na sequência (Figura 2).

Figura 2 - Fluxograma realizado para transformação de referencial e atualização das coordenadas de referência

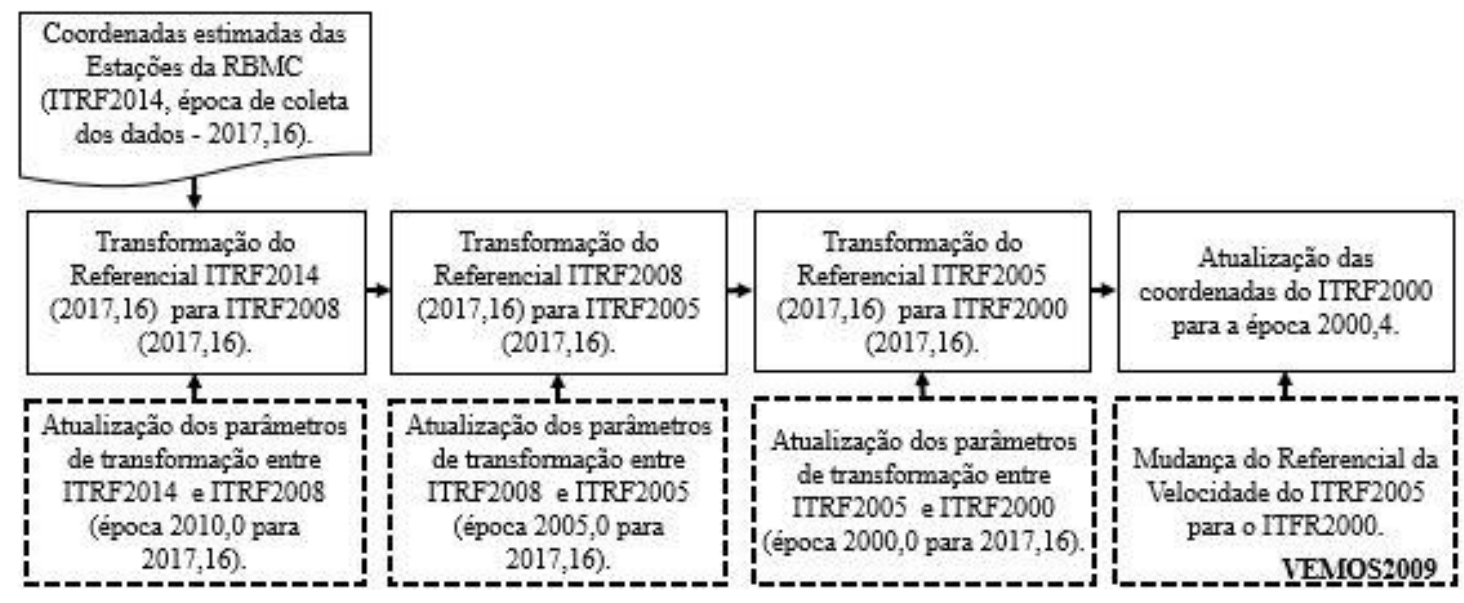

Fonte: Elaborada pelos autores.

A atualização dos parâmetros da época inicial to para a época $t$, pode ser obtida através da seguinte expressão (ITRF, 2017b) e (MONICO, 2008):

$$
P(t)=P_{t 0}+\dot{P}_{\left(t-t_{0}\right)}=\left(\begin{array}{c}
T_{X}(t) \\
T_{Y}(t) \\
T_{Z}(t) \\
S(t) \\
\varepsilon_{X}(t) \\
\varepsilon_{Y}(t) \\
\varepsilon_{Z}(t)
\end{array}\right)=\left(\begin{array}{c}
T_{X}\left(t_{0}\right) \\
T_{Y}\left(t_{0}\right) \\
T_{Z}\left(t_{0}\right) \\
S\left(t_{0}\right) \\
\varepsilon_{X}\left(t_{0}\right) \\
\varepsilon_{Y}\left(t_{0}\right) \\
\varepsilon_{Z}\left(t_{0}\right)
\end{array}\right)+\left(\begin{array}{c}
\dot{T}_{X} \\
\dot{T}_{Y} \\
\dot{T}_{Z} \\
\dot{S} \\
\dot{\varepsilon}_{X} \\
\dot{\varepsilon}_{Y} \\
\dot{\varepsilon}_{Z}
\end{array}\right)\left(t-t_{0}\right)
$$

Em que $\dot{P}$ é a taxa de variação dos parâmetros; $\vec{T}$ é o vetor das translações em X, Y e Z entre os dois referenciais, dadas em metros; $S$ é o fator de escala entre os dois referenciais, adimensional, dado em ppb (partes por bilhão); $\varepsilon$ é a matriz das rotações diferenciais em torno dos eixos $\mathrm{X}, \mathrm{Y}$ e Z, dadas em radianos; e $\dot{T}, \dot{S}$ e $\dot{\varepsilon}$ são as taxas de variações em translação, fator de escala, e rotação no ITRF com relação ao tempo, respectivamente.

Em seguida, realiza-se a transformação entre os sistemas de referência, por meio de três translações, três rotações e um fator de escala. De acordo com IERS Conventions (2010), a expressão matemática para transformar as 
coordenadas no sistema origem (o) para o sistema destino (d) é dada pela Equação 2, sendo que as coordenadas dos pontos nos dois sistemas devem estar na mesma época.

$$
\left[\begin{array}{l}
X \\
Y \\
Z
\end{array}\right]_{d}=\left[\begin{array}{l}
X \\
Y \\
Z
\end{array}\right]_{0}+\left[\begin{array}{l}
T_{X} \\
T_{Y} \\
T_{Z}
\end{array}\right]+\left[\begin{array}{ccc}
S & -\varepsilon_{Z} & \varepsilon_{Y} \\
\varepsilon_{Z} & S & -\varepsilon_{X} \\
-\varepsilon_{Y} & \varepsilon_{X} & S
\end{array}\right]\left[\begin{array}{l}
X \\
Y \\
Z
\end{array}\right]_{0}
$$

A última etapa refere-se à atualização das coordenadas das estações da época $\left(\mathrm{t}_{0}\right)$ para a época de interesse ( $\mathrm{t}$ ) e pode ser realizada de acordo com a Equação 3 (SIRGAS, 2018a):

$$
\left[\begin{array}{l}
X_{(t)} \\
Y_{(t)} \\
Z_{(t)}
\end{array}\right]=\left[\begin{array}{l}
X_{\left(t_{0}\right)} \\
Y_{\left(t_{0}\right)} \\
Z_{\left(t_{0}\right)}
\end{array}\right]+\left[\begin{array}{l}
V_{X} \\
V_{Y} \\
V_{Z}
\end{array}\right] *\left[t-t_{0}\right]
$$

Sendo $t$ a época de interesse; $\mathrm{t}_{0}$ a época de origem; $\mathrm{X}\left(\mathrm{t}_{0}\right), \mathrm{Y}\left(\mathrm{t}_{0}\right), \mathrm{Z}\left(\mathrm{t}_{0}\right)$ são as coordenadas cartesianas geocêntricas de uma estação na época de origem; $\mathrm{X}(\mathrm{t}), \mathrm{Y}(\mathrm{t}), \mathrm{Z}(\mathrm{t})$ são as coordenadas cartesianas geocêntricas de uma estação na época de interesse; e $V_{X}, V_{Y}$ e $V_{Z}$ é o vetor velocidade do ponto $\mathrm{X}\left(\mathrm{t}_{0}\right), \mathrm{Y}\left(\mathrm{t}_{0}\right), \mathrm{Z}\left(\mathrm{t}_{0}\right)$, na época de origem.

Os parâmetros de transformação que relacionam o ITRF2005 e o ITRF2000, na época 2000,0, são fornecidos por Altamimi et al. (2007). Analogamente, parâmetros de transformação que relacionam o ITRF2008 e o ITRF2005, na época 2005,0, são fornecidos por Altamimi, Collilieux e Métivier (2012). Já os parâmetros de transformação que relacionam o ITRF2014 e o ITRF2008 são disponibilizados pelo ITRF (2017a).

As componentes do vetor velocidade das estações ( $\mathrm{Vx}, \mathrm{Vy}$ e $\mathrm{Vz}$ ), necessárias para a atualização de coordenadas foram calculadas empregando o modelo VEMOS2009 (modelo de velocidades para América do Sul e Caribe). Este modelo corresponde a uma grade de $1^{\circ} \times 1^{\circ}$ com velocidade horizontal conhecida (DREWES e HEIDBACH, 2012). Salienta-se que, devido ao VEMOS calcular as velocidades referenciadas ao ITRF2005, foi necessário realizar a mudança de referencial de velocidade do ITRF2005 para o 
ITRF2000. Informações sobre transformação de referencial de velocidade podem ser obtidas em Soler e Snay (2004).

$\mathrm{Na}$ análise de qual processamento apresentou um melhor desempenho entre o BSW e o serviço IBGE-PPP, realizou-se a avaliação da acurácia planimétrica e altimétrica das coordenadas estimadas.

De acordo com Mikhail e Ackerman (1976) e Monico et al. (2009) a acurácia se refere aos efeitos sistemáticos e aleatórios. Desse modo, na obtenção da tendência, foi realizado o cálculo das discrepâncias planimétricas entre as coordenadas estimadas no BSW e as oficiais. Já a precisão planimétrica para cada estação GNSS foi obtida com a resultante dos desvios padrão das coordenadas elipsoidais $(\varphi, \lambda)$ estimadas no BSW. Foi realizado o mesmo procedimento na obtenção da amostra de acurácias planimétricas referente ao processamento realizado no IBGE-PPP.

Assim como na planimetria, as acurácias altimétricas foram calculadas com base nos valores de tendência e precisão. A tendência foi obtida de acordo com os valores de discrepâncias entre as componentes altimétricas estimadas e oficiais das estações; já as precisões das estações estão relacionadas aos desvios padrão da altitude geométrica obtidas nos serviços PPP.

$\mathrm{O}$ cálculo da acurácia planimétrica e altimétrica pode ser obtido em conformidade com as Equações 4 e 5, respectivamente.

$$
\begin{aligned}
& A_{p}=\sqrt{D_{p(\text { metros })}{ }^{2}+\sigma_{p(\text { metros })^{2}}} \\
& A_{h}=\sqrt{\Delta_{h(\text { metros })}{ }^{2}+\sigma_{h(\text { metros })}{ }^{2}}
\end{aligned}
$$

Em que $D_{p}$ é a discrepância planimétrica das coordenadas elipsoidais, em metros; $\sigma_{p(\text { metros })}$ é a precisão da resultante planimétrica das coordenadas elipsoidais, em metros; $\Delta_{h \text { (metros) }}$ é a discrepância altimétrica, em metros; e $\sigma_{h(m e t r o s)}$ é a precisão altimétrica, em metros.

No cálculo da discrepância da resultante planimétrica, foram utilizadas as coordenadas elipsoidais $(\phi, \lambda)$. Como todas as coordenadas 
estimadas são cartesianas, empregou-se método direto de Bowring (1976) na transformação das coordenadas cartesianas para coordenadas elipsoidais $(\phi$, $\lambda, \mathrm{h}$ ), no mesmo referencial, sendo o elipsoide de referência o GRS80 (Geodetic Reference System 1980).

As Equações 6 e 7 demonstram como foram obtidas as discrepâncias da resultante planimétrica em unidades métricas, considerando o elipsoide GRS80.

$$
\left|\begin{array}{c}
\Delta_{\phi(\text { metros })} \\
\Delta_{\lambda(\text { metros })}
\end{array}\right|=\left|\begin{array}{c}
M *\left[\phi_{(\text {estimada })}-\phi_{(\text {referência })}\right]_{(\text {radianos })} \\
N * \cos \phi *\left[\lambda_{(\text {estimada })}-\lambda_{(\text {referência })}\right]_{(\text {radianos })}
\end{array}\right|
$$

Sendo M o raio de curvatura da seção meridiana e $\mathrm{N}$ o raio de curvatura da seção primeiro vertical. Mais detalhes sobre o assunto podem ser encontrados em Brinker e Minnick (2012). A discrepância planimétrica em metros é obtida de acordo com expressão 7:

$$
D_{p(\text { metros })}=\sqrt{\Delta_{\phi(\text { metros })}^{2}+\Delta_{\lambda(\text { metros })}^{2}}
$$

Adjacente, a discrepância altimétrica em metros é dada pela Equação 8:

$$
\Delta_{h(\text { metros })}=h_{(\text {estimada })}-h_{(\text {referência })}
$$

Em relação ao cálculo das precisões planimétricas das coordenadas estimadas das estações da RBMC $\left(\sigma_{p}\right)$, considera-se a expressão 9.

$$
\sigma_{p}=\sqrt{\sigma_{\phi(m e t r o s)}^{2}+\sigma_{\lambda(\text { metros })}^{2}}
$$

Sendo $\sigma_{\phi(\text { metros })}$ e $\sigma_{\lambda \text { (metros) }}$ as precisões na latitude e longitude. No entanto, para obter os valores de desvio padrão das coordenadas, é necessário propagar as variâncias, pois o BSW fornece apenas os desvios padrão para as coordenadas cartesianas (X, Y e Z), e é preciso tê-los para as coordenadas elipsoidais $(\phi, \lambda, h)$. Detalhes sobre esse processo podem ser encontrados em Soler (1976). 


\section{Resultados e Análises}

\subsection{Acurácias Planimétricas}

Os resultados referentes às acurácias planimétricas para as 90 estações são ilustrados através das Figuras 3, 5 e 7, relativo ao processamento no BSW. Já os resultados referentes às acurácias planimétricas do processamento realizado no IBGE-PPP são ilustrados através das Figura 4, 6, e 8. Todos os gráficos foram construídos com escala em unidade métrica, com amplitude igual a 0,25 metro (valor padronizado para facilitar a comparação visual). A Tabela 1 é apresentada para auxílio na posterior identificação das estações nos resultados apresentados.

Tabela 1 - Estações da RBMC utilizadas

\begin{tabular}{ll|ll|ll|ll|ll|ll}
\hline 1 & AMCO & 16 & CEFT & 31 & MGUB & 46 & PIFL & 61 & ROSA & 76 & SPBP \\
\hline 2 & AMMU & 17 & CESB & 32 & MSAQ & 47 & PITN & 62 & RSAL & 77 & SPC1 \\
\hline 3 & AMTE & 18 & CHPI & 33 & MSDR & 48 & POAL & 63 & RSCL & 78 & SPDR \\
\hline 4 & AMUA & 19 & CRAT & 34 & MTCN & 49 & POLI & 64 & RSPE & 79 & SPFE \\
\hline 5 & APLJ & 20 & CUIB & 35 & MTCO & 50 & POVE & 65 & SAGA & 80 & SPFR \\
\hline 6 & BABJ & 21 & EESC & 36 & MTJI & 51 & PPTE & 66 & SALU & 81 & SPJA \\
\hline 7 & BABR & 22 & GOGY & 37 & MTNX & 52 & PRCV & 67 & SAVO & 82 & SPLI \\
\hline 8 & BAIL & 23 & IFSC & 38 & NEIA & 53 & PRGU & 68 & SCCH & 83 & SPS1 \\
\hline 9 & BAIT & 24 & IMBT & 39 & ONRJ & 54 & PRMA & 69 & SCLA & 84 & SPTU \\
\hline 10 & BATF & 25 & IMPZ & 40 & PASM & 55 & RIOD & 70 & SEAJ & 85 & SSA1 \\
\hline 11 & BELE & 26 & MABB & 41 & PBCG & 56 & RJCG & 71 & SJRP & 86 & TOGU \\
\hline 12 & BOAV & 27 & MGBH & 42 & PBJP & 57 & RNNA & 72 & SJSP & 87 & TOPL \\
\hline 13 & BRAZ & 28 & MGIN & 43 & PEAF & 58 & RNPF & 73 & SMAR & 88 & UBA1 \\
\hline 14 & CEEU & 29 & MGMC & 44 & PEPE & 59 & ROCD & 74 & SPAR & 89 & UFPR \\
\hline 15 & CEFE & 30 & MGRP & 45 & PICR & 60 & ROJI & 75 & SPBO & 90 & VICO \\
\hline \multicolumn{7}{|c}{ Fonte: Elaborada pelos autores. } & & & &
\end{tabular}

A Figura 3, refere-se se às acurácias planimétricas entre as coordenadas estimadas no BSW (IGS14, época 2017,16) em relação às coordenadas oficiais (SIRGAS2000, época 2000,40). 
Figura 3 - Acurácias planimétricas $\left(\mathrm{A}_{\mathrm{P}}\right)$ entre as coordenadas estimadas no BSW (IGS14, época 2017,16) e as de referência (SIRGAS2000, época 2000,40)

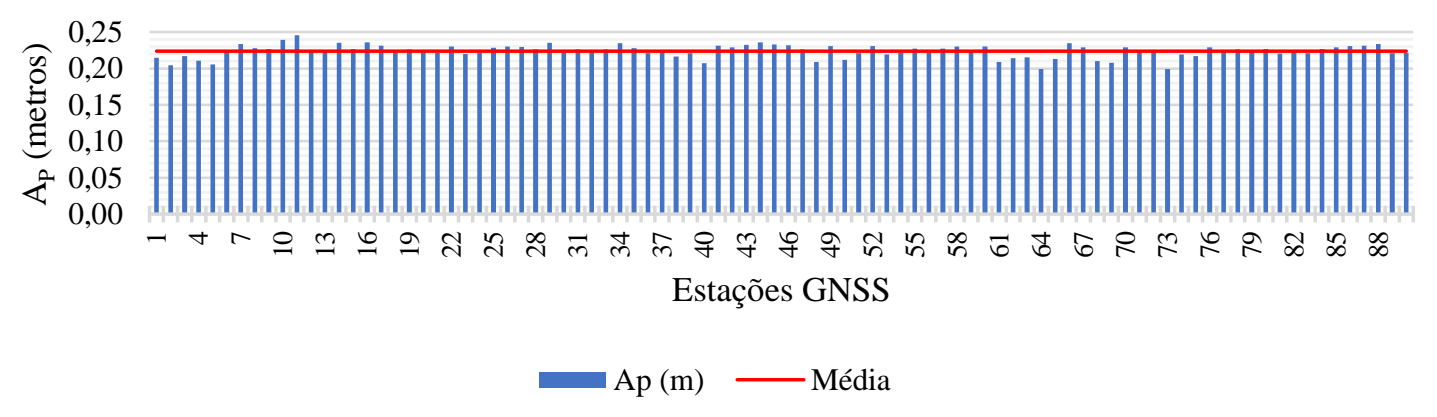

Fonte: Elaborada pelos autores.

A Figura 4 refere-se se às acurácias planimétricas entre as coordenadas estimadas no IBGE-PPP (IGS14, época 2017,16) em relação às coordenadas oficiais (SIRGAS2000, época 2000,40).

Figura 4 - Acurácias planimétricas entre as coordenadas estimadas no IBGE-PPP (IGS14, época 2017,16 ) e as de referência (SIRGAS2000, época 2000,40)

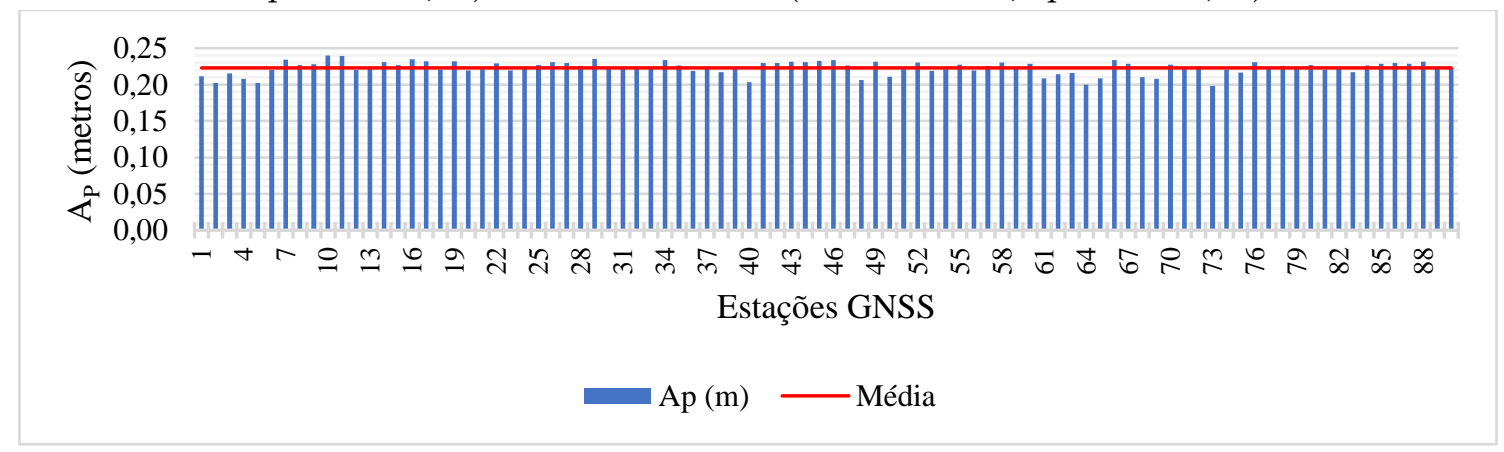

Fonte: Elaborada pelos autores.

Analisando as Figuras 3 e 4, ambas as amostras apresentaram porcentagem de 97,78 das acurácias planimétricas maiores que 0,20 metros (média de 0,224m). Essas acurácias já eram esperadas e estão relacionadas tanto, em relação aos referenciais distintos, quanto à evolução temporal das coordenadas entre a época 2017,16 para época 2000,40, além das precisões das resultantes planimétricas obtidas no processamento das coordenadas estimadas.

As Figuras 5 e 6 ilustram a segunda forma de análise, ou seja, a comparação entre as coordenadas estimadas (época 2017,16) e as de 
referência (época 2000,40), ambas no mesmo referencial (SIRGAS 2000). Desta forma, nessa etapa foi realizada a compatibilização dos referenciais, empregando os parâmetros de transformação disponibilizados pelo IGN.

As diferenças encontradas entre as amostras de acurácias planimétricas das Figuras 3 e 5 (em torno de 3,6 centímetros), retratam a mudança de referencial do IGS14 para o SIRGAS2000, de acordo com os parâmetros de transformação do IGN. O mesmo ocorre com as amostras de acurácias planimétricas referentes ao processamento realizado no serviço IBGE-PPP (Figuras 4 e 6).

Figura 5 - Acurácias planimétricas entre as coordenadas estimadas no BSW (SIRGAS2000, época 2017,16) e as de referência (SIRGAS2000, época 2000,40)

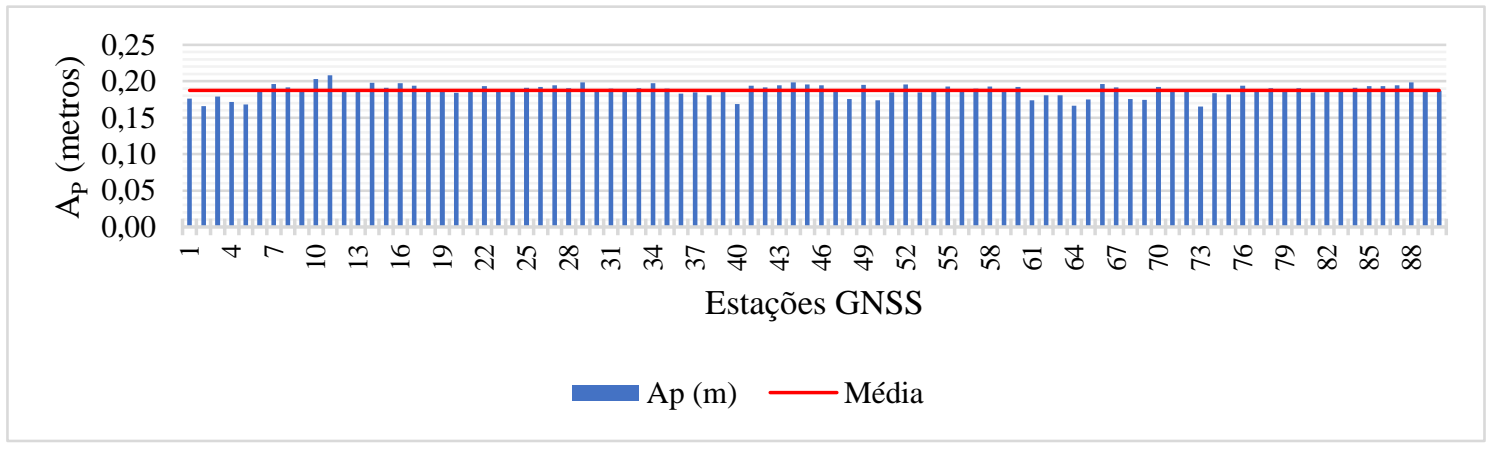

Fonte: Elaborada pelos autores.

Figura 6 - Acurácias planimétricas entre as coordenadas estimadas no IBGE-PPP

(SIRGAS2000, época 2017,16) e as de referência (SIRGAS2000, época 2000,40)

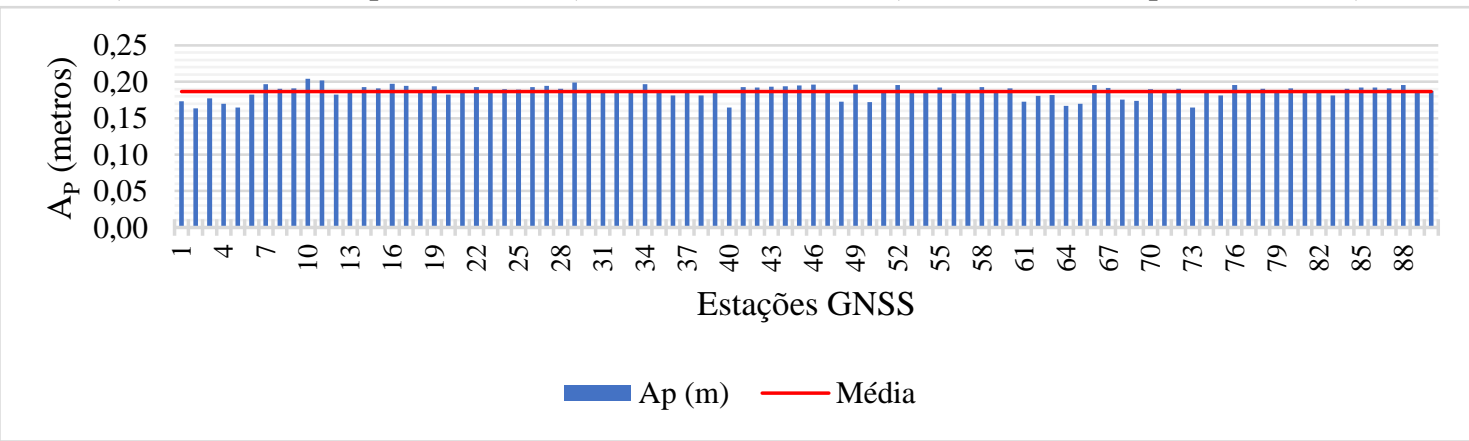

Fonte: Elaborada pelos autores.

A Figura 7 corresponde à comparação entre as coordenadas estimadas no BSW e as de referência das estações, ambas referenciadas ao SIRGAS2000, época 2000,40 . 
Figura 7 - Acurácias planimétricas entre as coordenadas estimadas no BSW (SIRGAS2000, época 2000,40 ) e as de referência (SIRGAS2000, época 2000,40)

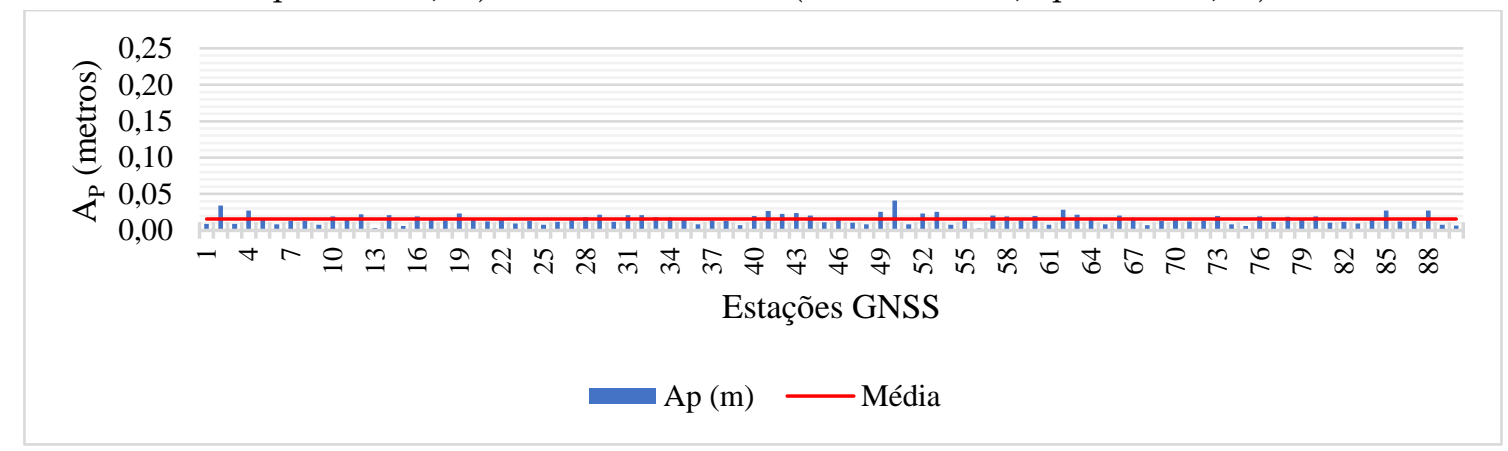

Fonte: Elaborada pelos autores.

A Figura 8 refere-se se às acurácias planimétricas entre as coordenadas estimadas no IBGE-PPP e as de referência das estações, ambas referenciadas ao SIRGAS2000, época 2000,40.

Figura 8 - Acurácias planimétricas entre as coordenadas estimadas no IBGE-PPP (SIRGAS2000, época 2000,40) e as de referência (SIRGAS2000, época 2000,40)

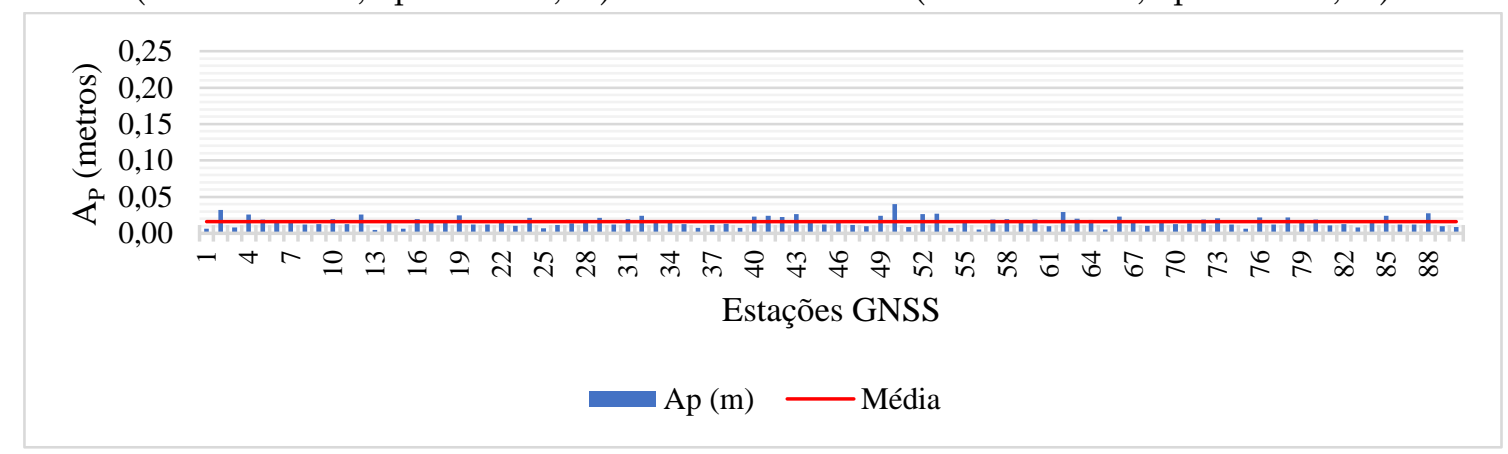

Fonte: Elaborada pelos autores.

Analisando amostra da Figura 7, 73,33\% das acurácias planimétricas do BSW foram menores que 2 centímetros. Este resultado foi bem similar ao apresentado na Figura 8, referente ao serviço IBGE-PPP, na qual amostra de acurácias foi de 74,44\%. Ressalta-se que na atualização das coordenadas estimadas tanto no BSW quanto no serviço IBGE-PPP, foi empregue o modelo de velocidade VEMOS2009.

Tipicamente, é conhecido que a solução do PPP é mais afetada pelas variações temporais das coordenadas, visto que as velocidades das componentes $\mathrm{N}$ e E das estações da RBMC são em torno de 1cm/ano (SILVA 
e COSTA, 2008). Portanto, espera-se que após aproximadamente 18 anos (época 2017,16 para à época 2000,4), as discrepâncias planimétricas sejam da ordem de $20 \mathrm{~cm}$. Já o uso de distintos sistemas de referência tem um impacto na ordem de milímetros como pode ser observado na Tabela 2. Desse modo, nota-se a importância, do processo de transformação de referencial e atualização de coordenadas, além da mudança do referencial de velocidade, em aplicações geodésicas de alta precisão.

Tabela 2 - Parâmetros de transformação dos referenciais disponibilizados pelo IGN, e atualização dos mesmos para época 2017,16

\begin{tabular}{|c|c|c|c|c|c|c|c|}
\hline & \multicolumn{2}{|c|}{ ITRF2005-ITRF2000 } & \multicolumn{2}{|c|}{ ITRF2008-ITRF2005 } & \multicolumn{2}{|c|}{ ITRF2014-ITRF2008 } \\
\hline & & Época 2000 & Época 2017,16 & Época 2005 & Época 2017,16 & Época 2010 & Época 2017,16 \\
\hline \multirow{7}{*}{ 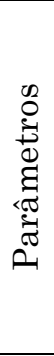 } & $T_{X}(\mathrm{~mm})$ & 0,1 & $-3,3$ & $-0,5$ & 3,1 & 1,6 & 1,6 \\
\hline & $T_{Y(\mathrm{~mm})}$ & $-0,8$ & 0,9 & $-0,9$ & $-0,9$ & 1,9 & 1,9 \\
\hline & $T_{Z}(\mathrm{~mm})$ & $-5,8$ & $-36,7$ & $-4,7$ & $-4,7$ & 2,4 & 2,3 \\
\hline & $S_{(p p b)}$ & 0,40 & 1,80 & 0,94 & 0,94 & $-0,02$ & 0,20 \\
\hline & $\varepsilon_{X}(\mathrm{mas})$ & 0,0 & 0,0 & 0,0 & 0,0 & 0,0 & 0,0 \\
\hline & $\varepsilon_{Y}$ (mas) & 0,0 & 0,0 & 0,0 & 0,0 & 0,0 & 0,0 \\
\hline & $\varepsilon_{Z}$ (mas) & 0,0 & 0,00 & 0,0 & 0,0 & 0,0 & 0,0 \\
\hline \multirow{7}{*}{ 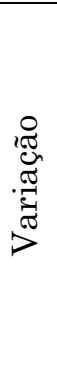 } & $\dot{T}_{X}(\mathrm{~mm} / \mathrm{ano})$ & $-0,20$ & $-3,4$ & 0,3 & 3,6 & 0,0 & 0,0 \\
\hline & $\dot{T}_{Y(\mathrm{~mm} / \mathrm{ano})}$ & 0,1 & 1,7 & 0,0 & 0,0 & 0,0 & 0,0 \\
\hline & $\dot{T}_{Z}(\mathrm{~mm} / \mathrm{ano})$ & $-1,8$ & $-30,9$ & 0,0 & 0,0 & $-0,1$ & $-0,07$ \\
\hline & $S_{\text {(ppb/ano) }}$ & 0,08 & 1,40 & 0,00 & 0,00 & 0,030 & 0,22 \\
\hline & $\dot{\varepsilon}_{X}$ (mas/ano) & 0,0 & 0,0 & 0,0 & 0,0 & 0,0 & 0,0 \\
\hline & $\dot{\varepsilon}_{Y}$ (mas/ano) & 0,0 & 0,0 & 0,0 & 0,0 & 0,0 & 0,0 \\
\hline & $\dot{\varepsilon}_{Z}$ (mas/ano) & 0,0 & 0,0 & 0,0 & 0,0 & 0,0 & 0,0 \\
\hline
\end{tabular}

mm:milímetro e mas: milisegundo de arco.

Fonte: Adaptado de Altamimi et al. (2007); Altamimi, Collilieux e Métivier (2012) e ITRF (2017a).

\subsection{Acurácias Altimétricas}

Os resultados referentes às acurácias altimétricas para as 90 estações são ilustrados através das Figuras 9, 11 e 13, relativo ao processamento no BSW. Já as amostras de acurácias altimétricas do processamento realizado no IBGE-PPP são ilustrados através das Figura 10, 12, e 14. Todos os gráficos foram construídos com escala em unidade métrica, com amplitude igual a 0,15 metros. 
Nas Figuras 9 e 10, as acurácias altimétricas estão associadas às coordenadas estimadas (IGS14, época 2017,16), em relação às coordenadas oficiais (SIRGAS2000, época 2000,40), além das precisões das componentes altimétricas estimadas (h), no BSW e IBGE-PPP, respectivamente. Desta forma, os resultados apresentados na Figura 9 e 10, foram obtidos sem considerar a compatibilização de referenciais e épocas.

Figura 9 - Acurácias altimétricas $\left(\mathrm{A}_{\mathrm{h}}\right)$ entre as coordenadas estimadas no BSW (IGS14, época 2017,16) e as de referência (SIRGAS2000, época 2000,40)

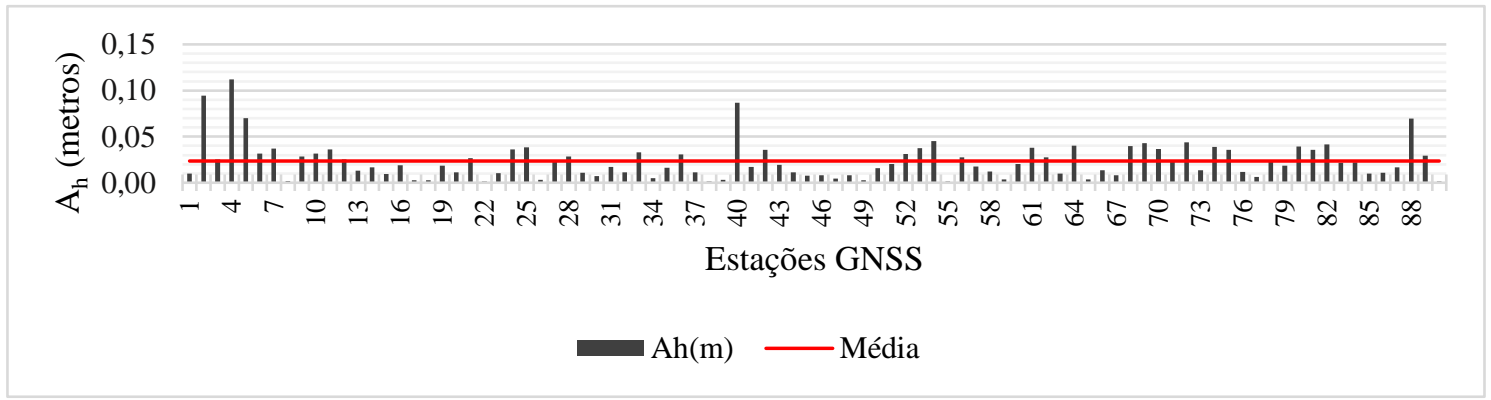

Fonte: Elaborada pelos autores.

Figura 10 - Acurácias altimétricas entre as coordenadas estimadas no IBGE-PPP (IGS14, época 2017,16) e as de referência (SIRGAS2000, época 2000,40)

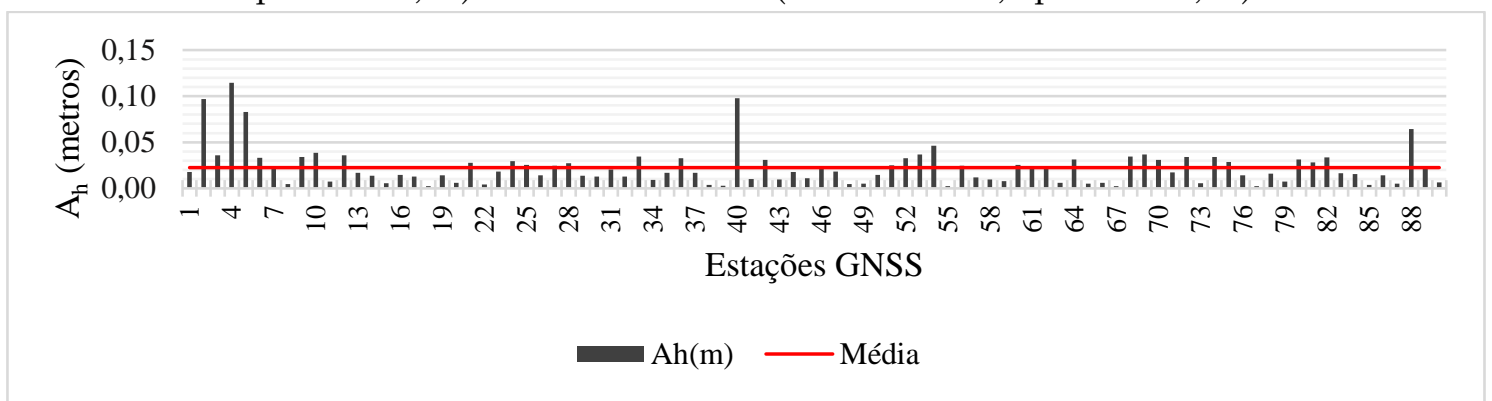

Fonte: Elaborada pelos autores.

Verifica-se na Figura 9 que 94,44\% da amostra de acurácias altimétricas foram menores que 0,050 metros, portanto, valores bem menores se comparados com as acurácias planimétricas (Figura 3). A amostra de acurácias da Figura 10 apresentou resultado análogo à amostra de acurácias altimétricas referentes às componentes altimétricas estimadas no BSW (Figura 9), em que 95,56\% dos valores são inferiores a 0,050 metros. 
As acurácias altimétricas entre as coordenadas estimadas (época 2017,16) e as de referência (época 2000,40), ambas no mesmo referencial (SIRGAS2000) são retratadas na Figura 11 para o BSW, e na Figura 12 para o IBGE-PPP.

A média das acurácias altimétricas da Figura 9 é de $0,026 \mathrm{~m}$, enquanto amostra representada na Figura 11 obteve o valor de média de $0,023 \mathrm{~m}$. Desse modo, as amostras de acurácias altimétricas referentes aos processamentos executados no BSW não apresentam diferenças expressivas (ordem de 3 milímetros) relativas à mudança dos referenciais do IGS14 para o SIRGAS2000.

Figura 11 - Acurácias altimétricas entre as coordenadas estimadas no BSW (SIRGAS2000, época 2017,16) e as de referência (SIRGAS2000, época 2000,40)

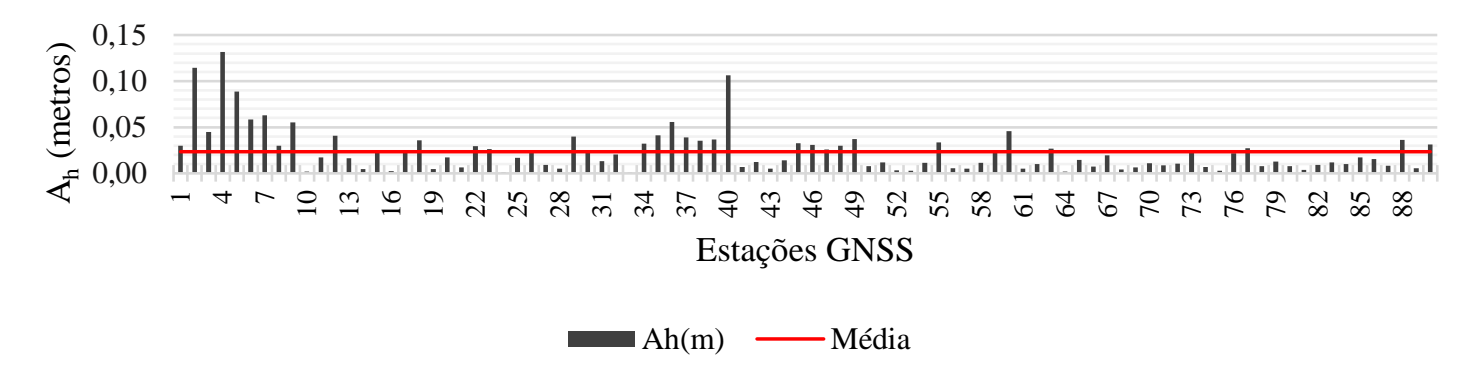

Fonte: Elaborada pelos autores.

Figura 12 - Acurácias altimétricas entre as coordenadas estimadas no IBGE-PPP (SIRGAS2000, época 2017,16) e as de referência (SIRGAS2000, época 2000,40)

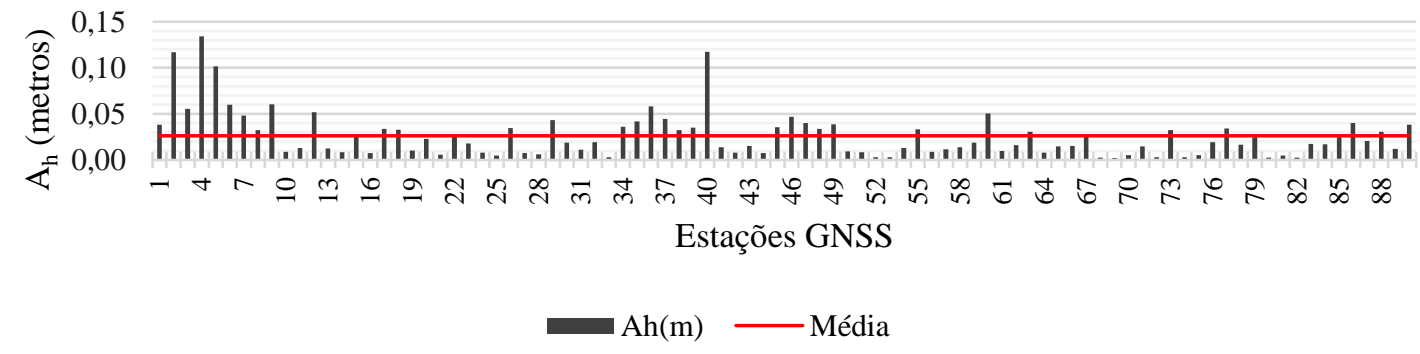

Fonte: Elaborada pelos autores.

Constata-se que as acurácias altimétricas relacionadas ao processamento realizado no IBGE-PPP (Figuras 10 e 12) também não 
apresentaram diferenças significativas como observado na componente planimétrica.

As Figuras 13 e 14 correspondem às acurácias altimétricas entre as coordenadas estimadas e as de referência das estações, no BSW e no IBGEPPP, respectivamente, ambas referenciadas ao SIRGAS2000, época 2000,40.

Comparando as amostras de acurácias altimétricas do BSW apresentadas na Figuras 11 (média 0,023m) e 13 (média 0,020m), observa-se que as acurácias altimétricas não apresentaram grandes diferenças entre as metodologias propostas neste estudo. $\mathrm{O}$ mesmo acontece com as acurácias altimétricas relacionadas ao processamento realizado no IBGE-PPP (Figuras 12 e 14). Isso se deve ao uso do modelo de velocidade VEMOS2009, que só é valido para movimentos horizontais, como se encontra declarado na página oficial do SIRGAS (SIRGAS, 2018b). Portanto, não é possível analisar a evolução temporal na componente altimétrica.

Figura 13 - Acurácias altimétricas entre as coordenadas estimadas no BSW (SIRGAS2000, época 2000,40) e as de referência (SIRGAS2000, época 2000,40)

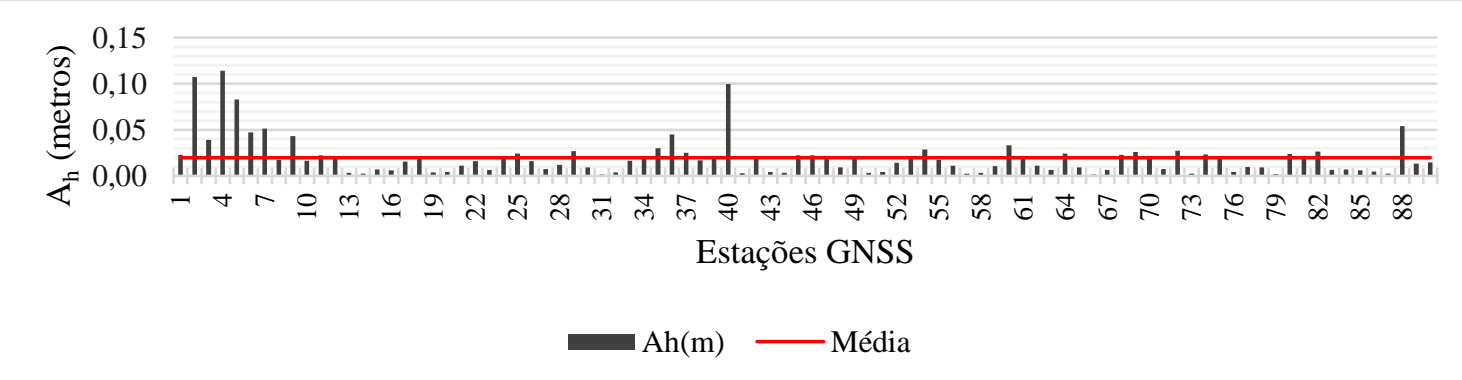

Fonte: Elaborada pelos autores.

Figura 14 - Acurácias altimétricas entre as coordenadas estimadas no IBGE-PPP

(SIRGAS2000, época 2000,40) e as de referência (SIRGAS2000, época 2000,40)

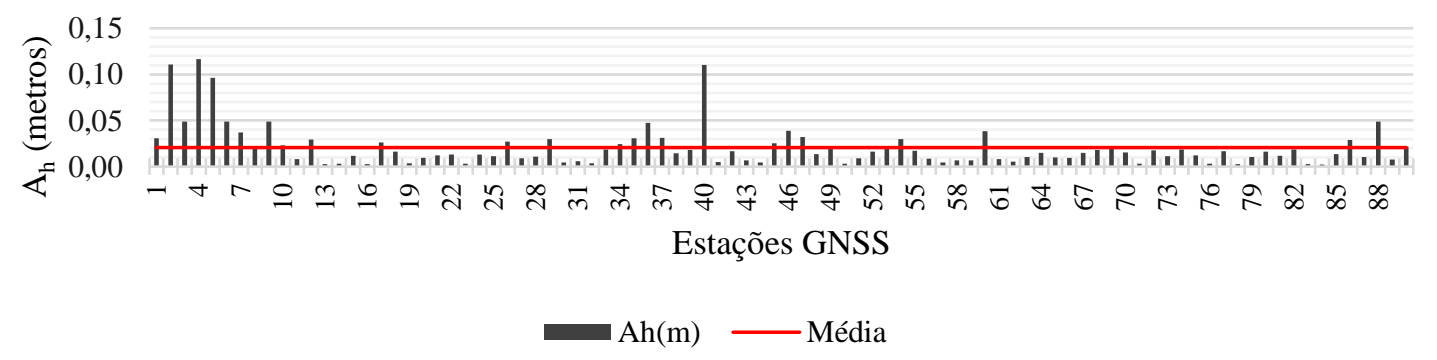

Fonte: Elaborada pelos autores. 
Destaca-se que sete estações da RBMC utilizadas neste estudo participaram da realização SIRGAS2000. No processamento da campanha GPS SIRGAS2000 foi utilizado um ajustamento combinado com as coordenadas cartesianas e suas matrizes variância-covariância obtidas por três centros: O IBGE, DGFI (Deutsches Geodätisches Forschungsinstitut) e BEK (Bayerische Kommission für die Internationale Erdmessung). O DGFI e o IBGE realizaram o processamento através do uso de observação de dupla diferença de fase em 3 sub-redes, e 9 sub-redes, respectivamente. Já o BEK fez uso de observações de fase e código no posicionamento isolado e preciso. $\mathrm{O}$ DGFI e o IBGE utilizaram o BSW, v. 4.0, enquanto que o BEK processou com o software GIPSY/OASIS II (SIRGAS, 2019).

Algumas características adotadas no processamento da campanha SIRGAS2000 pelo IBGE são descritas a seguir (COSTA et al., 2002): Não foi utilizado um modelo troposférico a priori; correção do atraso troposférico foi estimada a cada 2 horas; uso da função de mapeamento de Niell para componente hidrostática; estimativa dos parâmetros de gradiente troposférico adotando-se a função de mapeamento tilting; e resolução das ambiguidades usando a estratégia QIF (Quasi Ionosphere Free) e os mapas globais de ionosfera, denominados de GIMs (Global Ionosphere Maps) do CODE, e o uso de produtos orbitais do IGS.

Desse modo, a configuração do processamento da campanha SIRGAS é diferente do processamento PPP no BSW deste estudo. Principalmente pelo método de posicionamento, produtos orbitais utilizados, modelagem a priori do atraso troposférico, função de mapeamento, modelo de gradiente, e a eliminação dos efeitos da ionosfera (Quadro 1). 
2.3 Análise das amostras de acurácia posicional para dias com índice geomagnético $(\mathrm{Kp})$ distintos.

Os efeitos de ordem superior da ionosfera (HOI) além de serem proporcionais ao TEC (Total Electron Content), são também proporcionais ao campo magnético da Terra e a máxima densidade de elétrons. Desse modo, estes efeitos podem afetar aplicações geodésicas de alta precisão, em períodos de alta atividade ionosférica (MARQUES, MONICO, e AQUINO, 2009; ZHOU, KUANG e CAI, 2018).

Há vários índices de monitoramento ionosféricos (irregularidades, cintilação e geomagnéticos). O índice Kp (Planetarische Kennziffer) é usado para determinar a intensidade e a duração de tempestades geomagnéticas. Estas tempestades afetam o comportamento do TEC e, de modo consequente, o posicionamento GNSS (MATSUOKA et al.,2013; LOPES e MARQUES; 2018).

Para o cálculo das correções dos termos de ordem superior da ionosfera no BSW, é necessário como input os produtos GIM que são gerados diariamente no CODE. Além disso, o modelo para essa correção emprega o mais realista modelo de campo geomagnético a partir do IGRF (International Geomagnetic Reference Field). Esses efeitos não são modelados no IBGE-PPP.

Em vista disso, foi realizado o processamento das observáveis GNSS das 90 estações para um dia com índice geomagnético $\mathrm{Kp}$ calmo e com distúrbio, no mês de março, junho, setembro e dezembro do ano de 2017. Os dias foram escolhidos de acordo com a lista disponibilizada pelo ISGI (The International Service of Geomagnetic Indices), com os cinco dias mais calmos e perturbados em um mês, derivados dos valores do índice Kp (ISGI, 2019).

Na Tabela 3 são apresentadas as estatísticas das amostras de acurácias planimétricas referentes aos dias escolhidos, para ambos os serviços PPP, considerando a transformação de referenciais e atualização de épocas. 
Tabela 3 - Estatísticas descritivas das amostras de acurácia planimétrica

\begin{tabular}{|c|c|c|c|c|c|c|c|c|c|c|}
\hline & & & & & & & Amp & tude & Desvio & adrão \\
\hline & Mês & $*_{\text {DOY }}$ & IBGE & BSW & IBGE & BSW & IBGE & BSW & IBGE & BSW \\
\hline \multirow{4}{*}{ 芒营 } & 03 & 60 & 0,016 & 0,016 & 0,017 & 0,017 & 0,036 & 0,038 & 0,007 & 0,007 \\
\hline & 06 & 167 & 0,017 & 0,016 & 0,018 & 0,018 & 0,039 & 0,045 & 0,007 & 0,007 \\
\hline & 09 & 251 & 0,014 & 0,014 & 0,015 & 0,016 & 0,037 & 0,038 & 0,007 & 0,007 \\
\hline & 12 & 339 & 0,017 & 0,017 & 0,018 & 0,019 & 0,033 & 0,036 & 0,006 & 0,007 \\
\hline \multirow{4}{*}{ حิ } & 03 & 79 & 0,014 & 0,016 & 0,016 & 0,018 & 0,044 & 0,038 & 0,007 & 0,007 \\
\hline & 06 & 155 & 0,015 & 0,014 & 0,017 & 0,016 & 0,037 & 0,038 & 0,007 & 0,007 \\
\hline & 09 & 269 & 0,017 & 0,015 & 0,018 & 0,016 & 0,040 & 0,037 & 0,007 & 0,007 \\
\hline & 12 & 337 & 0,017 & 0,017 & 0,019 & 0,018 & 0,036 & 0,035 & 0,007 & 0,007 \\
\hline
\end{tabular}

*DOY: Day Of Year do calendário corrido do ano de 2017.

Fonte: Elaborada pelos autores.

As estatísticas descritivas informadas na Tabela 3 reforçam que o PPP no BSW apresentou resultados de acurácia planimétrica análogos se comparado com os resultados obtidos no serviço online IBGE-PPP, mesmo em dias com maiores perturbações do índice $\mathrm{Kp}$. Isto é, as diferenças se apresentaram na quarta casa decimal.

Na Tabela 4 são apresentadas estatísticas descritivas das amostras de acurácias altimétricas para ambos os serviços PPP.

Tabela 4 -Estatísticas descritivas das amostras de acurácia altimétrica

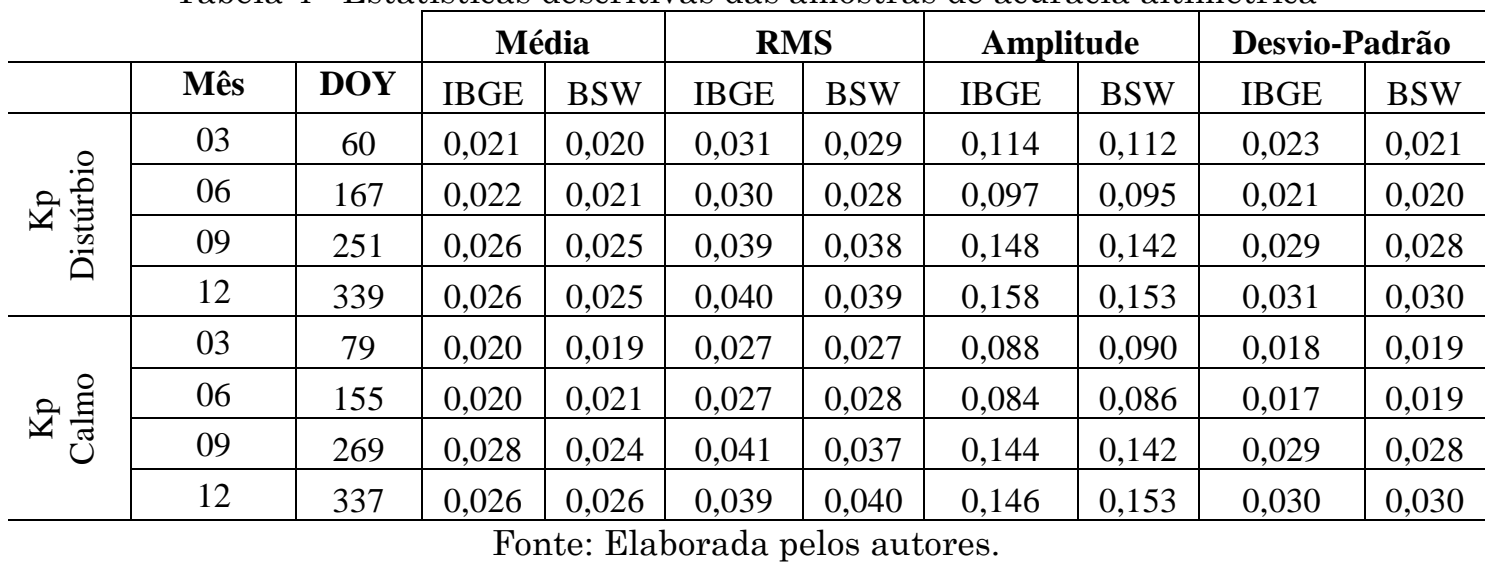

Constata-se pela Tabela 04 que além da média, as outras estatísticas descritivas da amostra de acurácias altimétricas do BSW foram análogas às do serviço IBGE-PP, em todos os dias analisados, tais como: o RMS e o desviopadrão. Portanto, as amostras de acurácias altimétricas do BSW e IBGE-PPP 
foram similares tanto nos dias com maiores perturbações do índice Kp, quanto nos dias calmos.

O BSW fornece uma gama de outras informações nos arquivos de resultados do processamento PPP. Dentre esses arquivos, têm os parâmetros troposféricos específicos do local, tais como, a componente úmida do atraso troposférico, o atraso zenital troposférico total, e a estimativa de gradientes troposféricos horizontais e seus respectivos RMS. Além do mais, o atraso zenital troposférico é estimado a cada 15 minutos. Desse modo, são estimadas 96 correções diárias por estação.

A componente hidrostática do atraso troposférico é calculada de acordo com um modelo troposférico. Na versão 5.2 do BSW, estão disponibilizados os seguintes modelos para redução dos efeitos da refração troposférica nos sinais GNSS usando a técnica PPP: Saastamoinen; Hopfield; Modelo de Niell (baseia-se no modelo Saastamoinen em conjunto com a função de mapeamento de Niell); VMF1/ECMWF; e GPT/GMF baseado nos dados de atmosfera do modelo GPT (Global Pressure and Temperature), usando o modelo Saastamoinen e a função de mapeamento GMF (Global Mapping Function). Além disso, o BSW aceita como input medições meteorológicas para os modelos troposféricos a priori ou arquivos ZPDs (Zenith Path Delays), obtidos com radiômetros de vapor de água.

É importante destacar que o IBGE-PPP fornece as correções e os desvios do atraso troposférico no zênite, ZWD e dos gradientes troposféricos. Esses valores podem ser acessados no arquivo *.pos (IBGE, 2017). No entanto, o usuário não pode alterar as estratégias de processamento dos dados. Por exemplo, como já destacado, para modelagem da troposfera há várias possibilidades de mitigação no BSW.

O BSW fornece como resultado do PPP, um modelo de ionosfera específico das estações de processamento, com os valores de TEC e seus respectivos RMSs. Também é disponibilizado um grid com valores de TEC referente ao um modelo regional ionosférico. 
Por fim, destaca-se que o BSW originalmente foi desenvolvido para processamento de dados GNSS em rede. A capacidade de processamento no modo PPP foi implementada na versão 5.0. Contudo, de acordo com os resultados apresentados, fica evidente a potencialidade de aplicação do BSW no PPP.

\section{Conclusões}

Ao compatibilizar os referenciais empregando os parâmetros fornecidos pelo o IGN, bem como a época das coordenadas, ambas as amostras de acurácias planimétricas diminuíram, na média, em torno de 14 vezes $(0,224$ $\mathrm{m}$ para $0,016 \mathrm{~m})$. Como esperado, o fator predominante na alteração das coordenadas se refere à evolução temporal das coordenadas, em função do movimento da placa Sul Americana, que ocorre, predominantemente, na direção noroeste. Isso comprova a necessidade de compatibilização dos referenciais e épocas das coordenadas, para trabalhos de precisão com uso do PPP.

A maioria dos parâmetros empregados no processamento no BSW foram escolhidos para a padronização com o serviço IBGE-PPP, visto que esse último, não permite alteração da estratégia de processamento. A diferença entre ambas, está relacionada com a modelagem da troposfera, e a inclusão da correção dos efeitos das cargas atmosféricas, e correções de ordem superior da ionosfera no BSW, além das diferenças entre os produtos orbitais usados.

Desse modo, o BSW permite uma maior flexibilidade no processamento, como alteração de modelos troposféricos, produtos orbitais, funções de mapeamento, modelos de gradientes horizontais, modificação do intervalo de observação, da máscara de elevação, dentre outros, além de calcular as correções de ordem superior da ionosfera no PPP. Contudo, o IBGE-PPP possui suas vantagens tais como, ser um serviço gratuito, online, e de fácil uso. 
Em relação as amostras de acurácias planimétricas e altimétricas considerando a transformação de referenciais e atualização de épocas, o BSW apresentou desempenho similar ao serviço IBGE-PPP, mesmo nos dias em que o índice Kp apresentavam distúrbios (060, 167, 251, e 339). Como não houve diferenças significativas nas estatísticas descritivas das amostras de acurácias entre o IBGE-PPP e o BSW nestes dias, recomenda-se para estudos futuros a análise das amostras de acurácias posicionais entre o IBGE-PPP e BSW, em dias nas quais ocorreram tempestades geomagnéticas classificada como intensas, como as ocorridas em 16 a 20 de março, e 31 de maio a 3 de junho de 2013, no ciclo solar 24 (RIBEIRO, 2016).

\section{Agradecimentos}

Esta pesquisa teve o incentivo da Universidade Federal de Viçosa através do Departamento de Engenharia Civil, curso de Pós-Graduação em Engenharia Civil/Informações Espaciais que disponibilizaram seus equipamentos, instalações e aplicativos computacionais.

Ao apoio financeiro que foi dado pela Coordenação de Aperfeiçoamento de Pessoal de Nível Superior - Brasil (CAPES) - Código de Financiamento 001.

\section{Contribuição dos autores}

A autora Franciele Lúcia Silva Braga realizou a pesquisa bibliográfica, o estabelecimento da metodologia, a seleção, organização e processamento dos dados, confecção dos gráficos e figuras, análises dos resultados, e a escrita e formatação nas regras do periódico. O Prof. Dr. William Rodrigo Dal Poz atuou na orientação e revisão durante a execução e submissão do artigo. 


\section{Referências}

ALMEIDA, M. S.; OLIVEIRA, G. D.; DAL POZ, W. R. Comparação de coordenadas de estações da RBMC transformadas e atualizadas para o ITRF2014. VI Simpósio Brasileiro de Ciências Geodésicas e Tecnologias da Geoinformação, Recife, 2016.

ALTAMIMI, Z.; COLLILIEUX, X.; LEGRAND, J. GARAYT, B. e BOUCHER, C. ITRF2005: A new release of the International Terrestrial Reference Frame based on time series of station positions and Earth Orientation Parameters, J. Geophys. Res., vol. 112, 2007. pp.1-19.

ALTAMIMI, Z.; COLLILIEUX, X. e MÉTIVIER, L. Analysis and results of ITRF2008. (IERS Technical Note; 37) Frankfurt am Main: Verlag des Bundesamts für Kartographie und Geodäsie, 2012. 54 pp.

BOWRING, B.R.; Transformation from spatial to geographical coordinates. Survey Review, XXIII, 181, 1976. pp. 323-327.

BRINKER, R.C.; MINNICK, R. The Surveying Handbook. $2^{\mathrm{a}}$.ed. Springer Science and Business Media, $2012.967 \mathrm{p}$.

BRAGA, F. L. S.; DAL POZ, W. R. Mudança de referencial e atualização de coordenadas entre o IGS14 (ITRF2014) e o SIRGAS2000 (ITRF2000). Anais do $4^{\circ}$ Simpósio Brasileiro de Geomática (SBG), Presidente Prudente, 2017. pp .543-550.

CARVALHO, A. S.; DAL POZ, W. R. Posicionamento geodésico referenciado ao SIRGAS2000 (ITRF2000) com base em serviços e ferramentas gratuitas disponíveis na internet. Anais do $5^{\circ}$ Simpósio Brasileiro de Ciências Geodésicas e Tecnologias da Geoinformação, Recife, 2014. pp. 12-14.

COSTA, S.M.A.; JUNIOR, E.S.F.; FAZAN J.A.; MONICO, J.F.G.; CAMARGO, P.O. Preliminary Results of SIRGAS 2000 Campaign — IBGE Analysis Center. In: Drewes H., Dodson A.H., Fortes L.P.S., Sánchez L., Sandoval P. (eds) Vertical Reference Systems. International Association of Geodesy Symposia, Springer, vol 124. Berlin, Heidelberg, 2002, pp 306-311.

CHEN, G.; HERRING, T. A. Effects of atmospheric azimuthal asymmetry on the analysis of space geodetic data. Journal of Geophysical Research, vol. 102, 1997.pp 20489-20502. 
DACH, R.; SIMON, L.; WALSER, P; FRIDEZ, P. User manual of the Bernese GNSS Software 5.2, Switzerland: AIUB, 2015, 852p.

DREWES, H.; HEIDBACH, O. The 2009 Horizontal Velocity Field for South America and the Caribbean. In: Kenyon S., M.C. Pacino, U. Marti (Eds.), "Geodesy for Planet Earth", IAG Symposia, 2012, pp. 657-664.

IBGE, Instituto Brasileiro de Geografia e Estatística. Coordenação de Geodésia. Diretoria de Geociências. Manual do Usuário - Aplicativo Online IBGE-PPP Versão: janeiro 2017. 43p. Site: <http://www.ibge.gov.br/home/geociencias/geodesia/ppp/manual_ppp.pdf>, acessado em junho de 2017.

IBGE-PPP, Serviço de Posicionamento por Ponto Preciso on-line). Site: < http://www.ppp.ibge.gov.br/ppp.htm >, acessado em março 2017.

IERS Conventions (2010). Gérard Petit and Brian Luzum (eds.). IERS Technical Note 36. Frankfurt am Main: Verlag des Bundesamts für Kartographie und Geodäsie, 2010. $179 \quad$ p., $\quad$ ISBN $\quad 3-89888-989-6 . \quad$ Site <https://www.iers.org/IERS/EN/Publications/TechnicalNotes/tn36.html>, acessado em março de 2017.

ISGI, The International Service of Geomagnetic Indices. Site: < http://wdc.kugi.kyoto-u.ac.jp/wdc/expdata.html>, acessado em maio de 2019.

IGN, Institut National de L'Information Géographique et Forestière. Site: $<$ http://www.ignfi.fr/en/content/ign-has-published-new estimation-itrfinternational-terrestrial-reference-frame>, acessado em fevereiro 2017.

IGS, International GNSS Service. IGS Products. Site:< http://www.igs.org/news/igs14-reference-frame-transition>, acessado em fevereiro 2017.

ITRF (2017a), International Terrestrial Reference Frame. Site: <http://itrf.ign.fr/ITRF_solutions/2014/tp_14-08.php>, acessado em janeiro 2017.

ITRF (2017b), International Terrestrial Reference Frame. Site: <http://itrf.ensg.ign.fr/doc_ITRF/Transfo-ITRF2008_ITRFs.txt >, acessado em fevereiro 2017. 
LOPES, L. J.; MARQUES, H. A. S. Avaliação dos efeitos ionosféricos nos sinais GNSS e crelação com índices ionosféricos e geomagnéticos. In: X Colóquio Brasileiro de Ciências Geodésicas, 2018, Curitiba. Anais do X CBCG, 2018.

MARQUES, H.A.; MONICO, J. F. G.; AQUINO, M. Efeitos de segunda e terceira ordem da ionosfera no posicionamento GNSS no Brasil. Revista Brasileira de Geofísica,2009.v.27, n.3, pp.354-374.

MATSUOKA, M. T.; COLLISCHONN, C.; KLEIN, I.; CAMARGO, P. O.; PEREIRA, V.A. S. Impacto de tempestade geomagnética na ionosfera e no posicionamento com GNSS: estudo de caso para 20 de novembro de 2003 na região brasileira. Boletim de Ciências Geodésicas, v. 19, n. 1, 2013.

MIKHAIL, E.; ACKERMAN, F. Observations and Least Squares. University Press of America, 1976. 497 p.

MONICO, J.F.G. Posicionamento pelo GNSS: Descrição, fundamentos e aplicações. $2^{\text {a }}$.ed. São Paulo: Editora UNESP, 2008. 476 p.

MONICO, J. F. M.; DAL PÓZ, A. P.; GALO, M.; SANTOS, M. C e OLIVEIRA, L. C. Acurácia e Precisão: Revendo os Conceitos de forma Acurada. Boletim de Ciências Geodésicas, séc. Comunicações, Curitiba, 2009. vol.15, nº3, pp.469-483.

RAY, R. D.; PONTE, R. M. Barometric tides from ECMWF operational analyses. Annales Geophysicae, vol. 21, 2003. pp.1897-1910.

REBISCHUNG, P. "Upcoming switch to IGS14/igs14.atx". 2016. Site: < https://igscb.jpl.nasa.gov/pipermail/igsmail/2016/008589.html>. acessado em março 2017.

RIBEIRO, B. A. G. Resposta Ionosférica as Tempestades Geomagnéticas desde a Região Equatorial até além da Crista da Anomalia de Ionização Equatorial, Durante o Ciclo Solar 24. Dissertação de Mestrado. Universidade do Vale do Paraíba, Programa Pós-Graduação em Física e Astronomia, São José dos Campos, 2016, 134p.

SILVA, A. L.; COSTA, S. M. A. Análises e Resultados do centro de processamento SIRGAS-IBGE. Anais do $2^{\circ}$ Simpósio Brasileiro de Ciências Geodésicas e Tecnologias da Geoinformação, Recife, 2008. pp. 000-000. 
SIRGAS (2018a), Uso de velocidades no processamento de dados GNSS. Site: $<$ http://www.sirgas.org/pt/velocity-model/using-velocities-gnss/>, acessado em fevereiro 2018.

SIRGAS (2018b), VEMOS: Modelo de velocidade para o SIRGAS. Site: < http://www.sirgas.org/pt/velocity-model/>, acessado em fevereiro 2018.

SIRGAS, SIRGAS2000. Site:<http://www.sirgas.org/pt/sirgasrealizations/sirgas2000/>, acessado em maio 2019 .

SOLER, T. On differential transformations between Cartesian and curvilinear (geodetic) coordinates. Rep 236. Dept Geod Sci Surv, Ohio State Univ, Columbus, Ohio, 1976.

SOLER, T; SNAY, R. A. Transforming positions and velocities between the International Terrestrial Reference Frame of 2000 e North American datum of 1983. Journal of Surveying Engineering. v. 130, n.2, 2004, pp. 49-55.

SOYCAN, M. A quality evaluation of precise point positioning within the Bernese GPS software version 5.0. Arabian Journal for Science and Engineering, v. 37, n. 1, 2012, pp. 147-162.

VMF1, Vienna Mapping Function. Site: <http: //ggosatm.hg.tuwien. ac.at/DELAY/GRID/VMFG/>, acessado em março 2019.

WESTON, N. D.; SOLER, T. Rigorous Geodetic Positioning in the Americas, 8th FIG Regional Conference Surveying towards Sustainable Development, Uruguay, 2012. pp.1-13.

ZHOU, Y.; KUANG, C.; CAI, C. Analysis of higher-order ionospheric effects on GNSS precise point positioning in the China area. Survey Review, 2018. pp. 1-8. 